\title{
Combining Delphi and Multiple Scenario Analysis for Planning Purposes
}

\author{
John F. Preble \\ and \\ Pradeep A. Rau \\ Department of Business Administration \\ University of Delaware \\ Newark, Delaware
}

A rapidly changing business environment has caused most firms to adopt some form of environmental assessment as part of their strategic planning process $(10$, p. $17 ; 12$, p. 12$)$. By monitoring the external environment on a regular basis, it is hoped that changing conditions will be detected sufficiently early so that plans and strategies can be developed to exploit opportunities and fight off threats. The Delphi technique and scenarios have been widely used to assess future conditions since such an assessment will help cope with rapid environmental change.

Delphi has been described as, ". . . a consensus technique that provides for the systematic solicitation and collation of judgments on a particular topic. This is done through a set of carefully designed sequential questionnaires interspersed with summarized information and feedback of opinions derived from earlier responses" $(13$, p. 157). The Delphi technique has been used frequently by various industry experts to generate a set of important future events in the external environment and their associated likelihoods.

A scenario is "an internally consistent view of what the future might turn out to be" $(11$, p. 446). Scenarios are written descriptions that help the planner to organize possible future events and issues and their interactions into a meaningful display. Since it is frequently desirable to consider several possible snapshots of the future simultaneously, often multiple scenarios or alternative futures are developed. The most common scenario is usually called the 'surprise free' or 'most likely' scenario. This can be compared to some extreme case, such as the 'worst case' or the 'best case' scenario. Multiple scenario analysis (MSA) as a process involves both the construction of several scenarios and their evaluation and comparison by individual firms. To illustrate this approach, three alternative scenarios are developed for which likelihood and impact evaluations are then made. Contingency plans can then be formulated for each alternative future. This study will provide a detailed illustration of how this approach might be applied by individual firms in the steel industry. However, this method may be applicable in other industries as well. 
The steel industry is in considerable trouble. The large integrated producers have recently accumulated substantial losses due to drastic decreases in demand and significant increases in steel imports. Meanwhile, the minimills, essentially scrap melting operations, are doing extremely well and increasing their share (2, pp. 24-25). Immediate action is necessary to forestall largescale retrenchment and pressures for protection abound. Mergers would allow for rationalization to take place, but antitrust provisions would first need to be relaxed (3, pp. 281-287). With this level of change taking place in the industry, it seemed like an excellent situation in which to employ our suggested approach.

\section{Scenario Formulation Process}

This paper suggests an approach which combines the Delphi technique with multiple scenario analysis (MSA) in order to plan better for the future. The various steps in the process - identification of events, likelihood estimation, scenario construction, impact assessment and favorability evaluation are discussed in detail. The results of this process are then incorporated into a contingency planning framework.

\section{Delphi}

The initial step in the scenario formulation process uses the Delphi Technique to forecast important future events in the steel industry along with an assignment of their individual likelihoods of occurrence. Selection of a Delphi panel is the first exercise that needs to be undertaken. The type of information and the judgments that need to be made would require the inputs of industry experts. The American Iron and Steel Institute, being the primary trade group in the industry, might be a logical choice to both administer the Delphi process and to provide the names of steel executives and steel industry analysts who could serve on the panel. In order to assure the reliablility of the Delphi estimates, a minimum panel size of 9 to 11 is suggested (6, p. 28). The steel executives or steel industry analysts, who might be quite dispersed geographically, need not actually meet to perform the exercise as questionnaires are used to develop the events and, in later rounds, to make the probability assignments. Preserving the anonymity of the individual participants' responses allows for a free flow of ideas and prevents domination by any one individual.

The actual Delphi process would be conducted in a sequence consisting of several steps. Initially, a set of key individuals from the American Iron and Steel Institute scans the economic and sociopolitical environment of the steel industry and comes up with a small number of events that are likely to have a significant impact on the industry in the near to intermediate future. A questionnaire depicting these events is then developed and sent out to study participants as round one. Participants are asked to add any additional significant events that would be likely to have an impact on the future of the steel industry. They are then asked to evaluate all of these events as to their likelihood of occurrence for the near to intermediate future on a scale ranging 
from zero (no likelihood) to one (strong likelihood). Participants then mail back the completed questionnaires to the administrator (American Iron and Steel Institute) who aggregates the data by averaging the likelihood estimates and determining the variance (extent of agreement of consensus with respect to the estimates). What is sought is a reasonable degree of consensus among panel members regarding important future events that may impact the steel industry and their likelihoods. To help achieve this objective, a second round questionnaire is sent out containing the same events and statistical feedback for the group in the form of some measure of central tendency (mean, median) and a measure of the degree of consensus achieved (variance, range). The participants are then asked to make new likelihood estimates, keeping in mind the round one group results. Individuals wishing to make new estimates that differ substantially from the round one group estimates are asked to either reconsider their estimate or detail, in the 'comment' section of the questionnaire, their rationale for making the estimate.

Round two responses are then processed by the administrator, and a determination is made as to whether a reasonable degree of consensus (agreement) has been achieved. If not, a round three questionnaire is sent out with the statistical feedback derived from round two and with any comments also indicated next to the trends to which they apply. Participants then evaluate this quantitative and qualitative information and make new likelihood estimates. Generally, three rounds are adequate to achieve the desired level of consensus, but additional rounds could be conducted as required. The results of such an exercise might look like what is shown in Table 1. Fifteen events have been suggested, the first ten coming from the economic environment of the steel industry and the last five from the sociopolitical environment. Likelihood assignments for the near to intermediate time horizon have been provided. With the events and likelihoods available, it is now possible to draft the actual scenarios at the firm level.

\section{Firm Level Scenario Analysis}

An approach by which individual firms in the steel industry would go about constructing the scenarios will now be described. It is noteworthy that while multiple scenario analysis has become increasingly popular as a planning tool in recent years, there exists no generally accepted way of drawing up scenarios and that informal approaches are the preferred methodology $(7$, p. 96; 8 , p. 45).

The first step in scenario development is for the firm to determine the type and number of scenarios that would be needed. Two examples of types of scenarios would be 'best case' - 'surprise free' - 'worst case,' and 'optimistic' - 'intermediate' - 'pessimistic.' It is generally accepted that three scenarios, properly characterized, are about the right number $(15$, p. 30). The task of writing these scenarios would be coordinated by a key executive; for example, C.E.O. or V.P. Planning. This manager, with the assistance of other knowledgeable executives would begin by taking the industry inputs; i.e., events and likelihoods generated by the Delphi process described earlier, which the 


\section{TABLE 1}

\section{DELPHI RESULTS FOR THE NEAR/INTERMEDIATE TERM}

\section{Economic Environment}

\section{Event}

Strong economic recovery Modest economic recovery Recession

Real interest rates drop

Real interest rates remain high

Value of \$ will go down

Value of \$ will stay at current levels

Value of \$ will go higher

Voluntary trade restrictions will be continued

Voluntary trade restrictions will

be removed

\section{Likelihood Estimate}

.4

.5

.1

.7

.3

.3

.4

.3

.2

.8

\section{Sociopolitical Environment}

\section{Event}

Labor concessions without demands

Some labor concessions with demands

No labor concessions

Antftrust laws relaxed

Antitrust laws not relaxed

\section{Likelihood Estimate}

.1

.6

.3

.3

Likelihood Scale

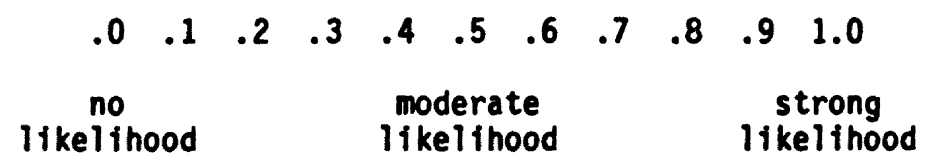


American Iron and Steel Institute has sent to the firm. These Delphi results provide the skeleton for the actual writing of the scenarios.

The second step would be to assemble the individual events in such a way as to get a continuum of future conditions in the environment. Figure 1 shows a sample of three scenarios which represent such a continuum. It should be noted that in these three alternative futures, the executives writing them have taken the events from Table 1 and have fleshed out their consequences and implied interactions into a meaningful display. This ensures the internal consistency of each scenario which was a requirement we had noted earlier (11, pp. 458, 461). The terms 'optimistic,' 'intermediate' and 'pessimistic' refer to the particular set of events contained in the respective scenarios and do not necessarily imply the nature of the impact on the individual firm. The intermediate scenario, for example, contains a mixed bag of events; while the optimistic and pessimistic scenarios contain the same events with positive and negative directions, respectively. The reason for including an integrated producer and a minimill in the illustration that follows is that they represent two extremes of a continuum of firms that make up the steel industry.

Table 2 illustrates how a large, integrated producer and a minimill can go about evaluating the favorability of the three scenarios. Taking the 15 events and their associated likelihoods provided earlier in Table 1 , the individual firm's executives then use the scale provided by Aaker (1, p. 105) to assess the impact each of these events would have on its organization. The scale ranges from -4 to +4 indicating a high negative impact (threat) or a high positive impact (opportunity), respectively. These impact assignments for a fully integrated producer and a minimill are provided in Table 2. The overall favorability of each type of scenario for a particular firm can then be computed by multiplying the events' likelihoods by the corresponding impact assessments and summing across events.

For example, the integrated producer arrived at an overall favorability rating of 6.7 for the optimistic scenario by multiplying $0.4 \times 4,0.7 \times 3,0.3$ $\times 3,0.2 \times 3,0.1 \times 3,0.3 \times 4$, and then summing these products. Similarly, the minimill computes a favorability rating for the optimistic scenario by multiplying $0.4 \times 0,0.5 \times-1,0.3 \times-3,0.2 \times 1,0.1 \times-2,0.3 \times-1$, which totals -1.9 .

Calculations are then made in a similar fashion for the intermediate and pessimistic scenarios. The integrated producer and the minimill are then in a position to rank the three scenarios based on their degree of favorableness (a combination of likelihood and impact) to their firm. These rankings are illustrated in the 'Totals' section of Table 2. The integrated producer finds the optimistic scenario the most favorable at 6.7 , while the minimill would rank the intermediate scenario as most favorable at 2.0. This highlights the differing situations in which these two types of firms find themselves. All this suggests that the integrated producer should use the most favorable scenario (in this case the optimistic scenario) as its core strategic basis while keeping the other two scenarios for its alternative plans. Similarly, the minimill would 


\section{TABLE 2}

SCENARIOS - LIKELIHOOD AND IMPACT COMPARISONS

Optimistic

Strong Recovery

Likelihood

Impact

Fully Integrated 4

Minimill

Interest Rates Drop Likelihood

Impact

Fully Integrated 3

Minimill

Value of Dollar Down

Likelihood

.3

Impact

Fully Integrated 3

Minimill

Voluntary Trade

Restrictions Continued

Likelihood

Impact

Fully Integrated 3

Minimill

Labor Concessions

without Demands

Likelihood

.1

Impact

Fully Integrated 3

Minimill
Intermediate

Modest Recovery

.5

1

$\frac{\text { Interest Rates Drop }}{7}$

0

1

Value of Dollar

Stays at Current Level

0
-1

Voluntary Trade Restrictions Continued .2

\section{1}

0

Labor Concessions

with Demands

.6

0

0
Pessimistic

Recession

.1

$-2$

$-1$

$\frac{\text { Interest Rates Remain High }}{3}$

$-3$

$-1$

Value of Dollar

$\frac{\text { Will Go Higher }}{.3}$

$-3$

0

\section{Voluntary Trade}

Restrictions Removed .8

$-2$

$-1$

No Labor Concessions

.3

$-3$

$-2$

Antitrust Laws Relaxed Antitrust Laws Not Relaxed Likelihood

$\frac{\text { Antitrust Laws Not Relaxed }}{.7}$

$\frac{\text { Antitrust Laws Not Relaxed }}{.7}$ Impact

Fully Integrated 4

Minimill

1

$-2$

\begin{tabular}{llll}
\hline Totals (Ranking) & & & \\
Fully Integrated & $6.7(1)$ & $1.4(2)$ & $-5.9(3)$ \\
Minimill & $-1.9(3)$ & $2.0(1)$ & $-0.4(2)$ \\
\hline
\end{tabular}




\section{EXHIBIT 1}

\section{STEEL INDUSTRY SCENARIOS}

\section{Optimistic}

The world economy will improve and the recovery will extend to all countries. Real interest rates and the value of the dollar will go down with a corresponding improvement in export possibilities. Meanwhile imports will decline and will continue to be capped by voluntary restrictions. Antitrust provisions will be relaxed allowing for rationalization of production facilities and swapping of operations. On the labor front, the unions will continue to decline in strength and will remain conciliatory and keep wages and benefits down.

\section{Intermediate}

The world economy will recover, though only, at a modest rate. Real interest rates will go down though the dollar will continue to be strong. The voluntary trade restrictions by steel producing countries will be maintained. Labor may make some concessions on wage rates and future increases but they will also demand a greater degree of job security in their contracts. Opportunities for steel manufacturers to swap facilities and rationalize their manufacturing plants will be difficult because of antitrust restrictions.

\section{Pessimistic}

The world economy will slip back into a prolonged recession. Interest rates in real terms will stay high and the dollar will grow even stronger. Under these conditions foreign steel producing countries will be opposed to any voluntary restrictions on steel exports. Labor will be increasingly reluctant to offer any concessions on wages and benefits. Meanwhile, government antitrust laws will be strictly enforced thus preventing stee 1 manufacturers from rationalizing their facilities. 
EXHIBIT 2

CONTINGENCY PLANNING FRAMEWORK

Type of Steel Company

Fully Integrated Producer

Minimill Producer
Planning Priorities

Basic Plan

Optimistic

Scenario

Intermediate

Scenario
Alternative Plans

$\begin{array}{cc}\text { Intermediate } & \text { Pessimistic } \\ \text { Scenario } & \text { Scenario }\end{array}$

Pessimistic Scenario
Optimistic

Scenario.

make the intermediate scenario as its primary focus while using the pessimistic and optimistic scenarios, respectively, in their back up plans. This is depicted as a contingency planning framework in Figure 2. While the point is not specifically addressed in this paper, each steel producer would then develop strategies and plans around these scenarios. It may be worth noting also that the entire exercise has both an industry-specific and a firm-specific component and mainly serves as a useful vehicle for getting the individual firm's planners and executives to put down their views of the future which can then be employed in a contingency framework for developing strategic plans.

\section{Summary}

Two popular techniques for environmental assessment are Delphi and multiple scenario analysis. These techniques were first reviewed and then it was shown how they could be combined in a planning situation. The steel industry was chosen for illustrative purposes, recognizing that this industry is faced with an uncertain future. Other industries facing similar levels of change might also employ such an exercise.

One of the advantages of using the approach suggested here is that it is relatively easy to adopt, and one does not have to generate more than three scenarios incorporating only the most important environmental changes. The idea is to help the firm's planners form contingency plans for a small number of alternative futures while simultaneously making it casier for them to switch from one plan to another as events unfold (14, pp. 15-16). Recent work in strategic planning has suggested the concept of 'dialectical inquiry,' which refers to the importance of focusing on the way problems are formulated or 
framed in organizations, rather than the actual solving of problems $(4$, p. 662; 9, pp. 129-131). Presumably, the very act of structuring the problem as suggested in the paper will improve the firm's ability to plan for an uncertain future.

Porter suggests that scenarios are powerful devices for taking uncertainty into account in strategic decision making. He further states that scenarios ". . . allow a firm to move away from dangerous, single-point forecasts of the future in instances when the future cannot be predicted. Scenarios can help encourage managers to make their implicit assumptions about the future explicit, and to think beyond the confines of existing conventional wisdom" $(11$, p. 447)

A limitation of the approach suggested in this paper is that it may be timeconsuming and require relatively widespread participation. Also, it is difficult to gauge pricisely exactly what the future might be. However, planning for the future of an organization is bound to be difficult; and widespread involvement by top executives is desirable. Glueck and Jauch provide perspective here when they summarize the use of scenarios at General Electric and Royal Dutch Shell (London): "It is not important whether the scenarios become the future. They are a training vehicle which stretches executives' minds so that they can deal more effectively with the future environment - whatever it is" (5, p. 120).

\section{References}

1. Aaker, David A., Strategic Market Management, New York: John Wiley And Sons, (1984), p. 105.

2. American Iron and Steel Institute, "Steel and America: Managing Dramatic Change," (May 1985), Annual Report, pp. 1-32.

3. Barnett, Donald F. and Louis Schorsch. Steel - Upheaval in a Basic Industry, Cambridge, MA: Ballinger Publishing Co., (1983), pp. 257290.

4. Eden, C., "Operational Research and Organizational Development," Human Relations, Vol. 31, (1978), pp. 657-674.

5. Glueck, W. F. and L. R. Jauch. Business Policy and Strategic Management, New York: McGraw-Hill, Inc., 4th Ed., (1984), p. 120.

6. Jain, Subhash C., "Predicting Impact of Change Using Delphi Technique," Managerial Planning, Vol. 23, (Sept./Oct.1974) pp. 20-28.

7. Linneman, Robert E. and Harold E. Klein, "The Use of Multiple Scenarios by U.S. Industrial Companies: A Comparison Study, 1977-1981," Long Range Planning, Vol. 16, No. 6, (1983), pp. 94-101. 
8. Malaska, P., M. Malmivirta, T. Meristo, and S. O. Hansen, "Scenarios in Europe - Who Uses Them and Why?," Long Range Planning, Vol. 17, No. 5, (1984), pp. 45-49.

9. Mason, R. O., and I. I. Mitroff. Challenging Strategic Planning Assumptions, New York: Wiley, (1981).

10. Mesch, Allen H., "Developing an Effective Environmental Assessment Function," Managerial Planning, Vol. 32, No. 5, (September 1978). pp. 12-17.

11. Porter, M. E., Competitive Advantage: Creating and Sustaining Superior Performance, New York: The Free Press, (1985), pp. 445-481.

12. Preble, John F., "Corporate Use of Environmental Scanning," Michigan Business Review, Vol. 30, No. 5, (September 1978), pp. 12-17.

13. Preble, John F., "The Selection of Delphi Panels for Strategic Planning Purposes," Strategic Management Journal, Vol. 5, No. 2, (1984), pp. 157-170.

14. Raubitschek, R. S., "Multiple Scenario Analysis and Business Planning," Colloquium on Scenario Planning and Competitive Strategy, Harvard Business School, Boston, MA, (1983), pp. 1-47.

15. Zentner, Rene D., "Scenarios in Forecasting," Chemical and Engineering News, Vol. 40, (October 6, 1975), pp. 22-24 and 29-34. 